\title{
Mechanical Performances of Twill Kenaf Woven Fiber Reinforced Polyester Composites
}

\author{
Siti Nor Azila Khalid, Al Emran Ismail", Muhd Hafeez Zainulabidin, Ahmad \\ Mubarak Tajul Arifin, Mohd Fahrul Hassan, Mohd Rasidi Ibrahim and \\ Mohammad Zulafif Rahim
}

Mechanical Failure Prevention and Reliability (MPROVE) Research Centre, Faculty of Mechanical and Manufacturing Engineering, Universiti Tun Hussein Onn Malaysia, 86400 Johor, MALAYSIA.

Received 7 May 2018; accepted 25 July 2018, available online 5 August 2018

\begin{abstract}
Natural fibres have the potential aspect to replace glass fibre reinforced composites. One of these fibers is kenaf. It is also one of the selected natural fibres that have bio resource profit regarding on their capability to absorb energy absorption especially. In order to prove the application of this fiber for the load-bearing application, the fiber in the form of yarn is weaved into fiber mat and reinforced with the plastic resin. This study focused on the twill yarn kenaf woven composite structure. Composites were prepared using the hand lay-up method with different type of orientation where the orientation is designed using Taguchi method. The hardened composites were cured for 24 hours in an ambient temperature before it was shaped according to ASTM D3039. The samples were then stressed uni-axially to obtain the stress-strain curves. The result shows the fiber orientations were significant factor in determining the performance of tensile strength. In this work, fiber mats are then optimized and the results showed that the values of tensile and modulus strength were $55.738 \mathrm{MPa}$ and 5761.704 Joule, which is increased $3.77 \%$ and $4.23 \%$ for tensile strength and Young modulus, respectively. By comparing fracture mechanism before and after optimizations, there was clear decreasing fracture surface. It indicated that, the mechanical behavior performances of the twill woven kenaf reinforced composites can be effectively improved by this method.
\end{abstract}

Keywords: Natural fiber; Composite; Energy absorption; Twill woven kenaf

\section{Introduction}

In the recent years, industries actively attempt to reduce the dependence on petroleum based fuels and products due to the increasing environmental consciousness. This leads to the need to investigate environmentally friendly and sustainable materials to replace the existing synthetic fibres [1-3]. The increase of production and usage of plastics in every sector of our daily life lead to massive plastic wastes. Disposal problems, as well as strong regulations and criteria for a cleaner and safer environment, have influenced such a great part of the scientific research towards ecocomposite materials. Among the different types of ecocomposites, those which contain natural fibres and natural polymers are the ones more preferred to be used. In the last few years, polymeric biodegradable matrices have become commercial products. However, their expensive price limits their widespread use. Currently, the most viable way toward eco-friendly composites is the use of natural fibres as reinforcement [1-4].

Composite structure are being increasingly used because they are attractive and perform better due to their enhanced physical and mechanical properties such as high strength, light weight and low manufacturing cost.
Most of the structural components in the vehicle industry are made of composite materials as their energy absorption capability that employed to produce a crashworthy structure subjected to axial or non-axial loading [3-5]. Natural fibres represent a traditional class of renewable materials which, nowadays, are experiencing a revival. In the recent years, there have been many researchers who emerged in the field of natural fibre reinforced plastics [6-10]. Most of the studies proposed composite as the target material, such as Glass Fibre Reinforced Polyester (GFRP) [11-13], Carbon Fibre Reinforced Polymer (CFRP) [14] and Fibre Reinforcement Polymer (FRP) [15].

There are few studies which deals with structural composites based on natural reinforcements. These studies are mainly oriented towards housing applications where structural panels and sandwich beams were manufactured out of natural fibres and used as roofs [6]. Considering the high-performance standard of composite materials in terms of durability, maintenance and cost effectiveness, the application of kenaf natural fibre reinforced composites as construction material holds enormous potential and is critical to achieve sustainability. Due to their low density and their cellular structure, natural fibres possess very good acoustic and 
thermal insulation properties and demonstrate many advantageous properties compared to fiberglass [16].

Natural plant fibres can be economically and ecologically useful alternative to reinforcement fibres in polymeric composites. Due to their low cost in comparison to conventional fibres, kenaf fibre reinforced composites have great potential to be use in engineering applications. A growing environmental awareness across the world has aroused interest in research and development of environmentally friendly and sustainable materials. Natural plant based fibre were used as reinforcements for composite materials and give various advantages compared to conventional fibres.

One of the main important aspects of the behaviour of natural plant fibre reinforced polymeric composites is their response to an impact load and the capacity of the composites to withstand their service life. Such damage may be caused by bumps or crashes, falling objects and debris. Some of the reported work [17] has suggested that natural fibre composites are very sensitive to impact loading. The major drawback is its low impact strength as compared to glass fibre reinforced thermoplastic and thermosets composites. In a broader context, assessing the impact resistance of a composite material is always hard since the damage manifests itself in different forms such as delamination at the interface, fibre breakage, matrix cracking and fibre pulls out.

Understanding the importance of kenaf as a potential for profit bio resource, the Malaysian National Kenaf and Tobacco Board (NKTB) announced nationwide cultivation process, which involve wide area and as many farmers in eight states in Malaysia in the year 2013 [18]. Based on their growth rate, kenaf are now involved in several provinces of Malaysia such as Pahang, Kelantan, Terengganu, Perak, Johore, Selangor, Negeri Sembilan and Malacca. Malaysian government considered kenaf as the next generation of major industrial crop in line with economic policy and development to create new sources and at the same time heavily promotes its production growth, to make it abundant, inexpensive and readily available. From the research reviews [19-21], these studies highlight to explore properties of industrial kenaf to project it as a prospective energy absorbing in the Malaysia which could be alternative sources of future energy demands in a growing population.

Akil et al., (2011) studied on kenaf fibre reinforced composite and concluded that one of the reasons kenaf was favoured in research area is because it has good mechanical properties especially in terms of specific modulus or density. Today, kenaf fibres, which acted as reinforcement of composite material, arouse research interests. In this research, kenaf natural fibre was selected based on their good mechanical properties. Fig 1 shows the comparison of specific modulus of kenaf fibre with several other fibres.

Kenaf fibre has very good characteristic compared to other natural fibres, i.e long fibre, small diameter, and high interfacial adhesion to matrix [22]. Kenaf is commercially available and economically cheaper amongst other natural fibres [18]. Other than that, kenaf is compliant to several types of soil to grow effectively and only need nominal chemical treatment [23]. However, there is only a few studies has been done on kenaf fibre to comprehensively understand the possibility of composites especially crashworthiness loading condition. In this research, tensile tests were carried out on woven kenaf reinforced unsaturated polyester composite. Kenaf natural fibre composite has been used in research area, but only small portion has exploited for woven kenaf.

This research is an attempt made to study the effect of woven kenaf fibre and orientation using Taguchi Method on energy absorption for polyester composites. To the best of knowledge [19-21,24], till now, there isn't any significant work has been done in this area by using Taguchi method to optimize mechanical behaviour from kenaf reinforcement. From previous research [8,21] various fibre volume fractions were analysed to study the effect of kenaf reinforcement on the impact properties. A low velocity instrumented was employed to determine stress-strain, Young modulus, tensile strength behaviour for evaluating the performance in terms of load bearing capabilities and failure modes. The value of mechanical behaviour of woven kenaf reinforced polyester composites were analysed using Minitab software and fabricated new sample to get optimal result of mechanical behaviour. The failure mechanism of fractured specimens was assessed by high camera resolution. The mechanical behaviour of woven kenaf reinforced polyester composites was analysed using Minitab software and their response characteristics were discussed.

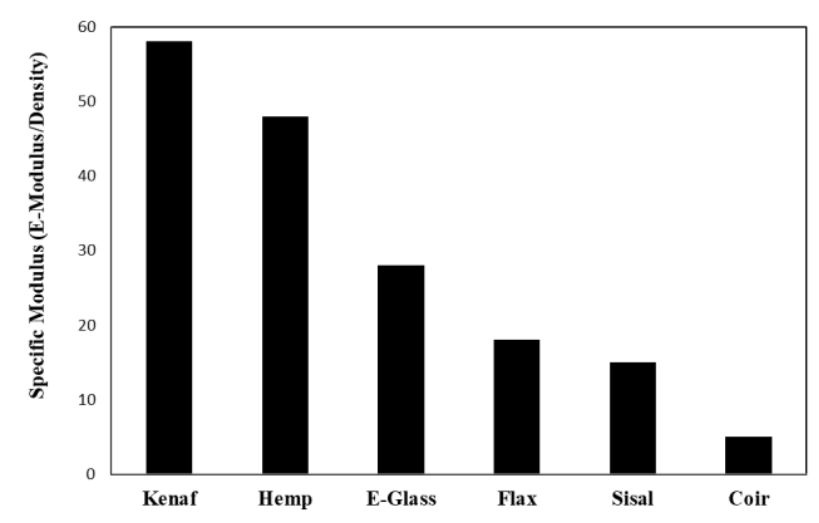

Fig. 1 Comparison of specific modulus of kenaf fibre with several other fibres $[6,19]$

\section{Experimental Procedure}

\subsection{Taguchi method and variables}

The Taguchi method involves reducing the variation in process through robust design of experiments [25]. Conventional experimental design procedures were too complicated and difficult to apply. The overall objective of the method was to produce high quality product at low cost to the manufacturers. This method was developed for designing experiments to investigate how various parameters affect the mean and variance of a process performance characteristic, thus define how well the 
process is functioning. The experimental design proposed by Taguchi [26-27] used orthogonal arrays to organize the parameters affecting the process and the level at which it should be varied. It allows the collection of the necessary data to determine which factor most affect product quality with minimum amount of experimentation, and at the same manner saving time and resources. Analysis of variance on the collected data from the Taguchi design of experiments can be used to select new parameter values to optimize the performance characteristic.

In this method, the general steps involving defining the test variables which affect the output parameter was varying orientation of angles from the layers. The $\mathrm{L}_{9}\left(3^{4}\right)$ orthogonal array was used based on the number of parameters and levels that has been selected. These parameters were layered four times and investigated at three different angles for each composite. Taguchi method was applied for composite that have 4 layers [30] with different type of woven. The selected angle was suggested by [7, 31]. Orthogonal arrays were then created for the parameter design indicating the orientation of each layer for experimental purposes. The arrangement of angle and trial for the experiment by using Taguchi method $\mathrm{L}_{9}\left(3^{4}\right)$ is as shown in Tables 1 . Table 2 shows the rules of Taguchi method, whereas Table 3 shows the trial angle in experiment using orientation from Taguchi method. Next, experiment was conducted according to the completed array to collect the data on their effects towards the composite performance, and lastly data analysis was completed to determine the effects of different parameters towards composite performance.

Table 1 The arrangement of angle $\left[-15^{\circ} / 40^{\circ} / 75^{\circ}\right]$ using Taguchi method.

\begin{tabular}{ccccc}
\hline Indicator & Parameter & 1 & 2 & 3 \\
\hline A & $1^{\text {st }}$ layer & -15 & 40 & 75 \\
B & $2^{\text {nd }}$ layer & -15 & 40 & 75 \\
C & $3^{\text {th }}$ layer & -15 & 40 & 75 \\
D & $4^{\text {th }}$ layer & -15 & 40 & 75 \\
\hline
\end{tabular}

Table 2 Taguchi method rules

\begin{tabular}{ccccc}
\hline Trial & A & B & C & D \\
\hline 1 & 1 & 1 & 1 & 1 \\
2 & 1 & 2 & 2 & 2 \\
3 & 1 & 3 & 3 & 3 \\
4 & 2 & 1 & 2 & 3 \\
5 & 2 & 2 & 3 & 1 \\
6 & 2 & 3 & 1 & 2 \\
7 & 3 & 1 & 3 & 2 \\
8 & 3 & 2 & 1 & 3 \\
9 & 3 & 3 & 2 & 1 \\
\hline
\end{tabular}

The most important stage in the design of experiment is selection of the control factor. Therefore, a large number of factors were included so that non-significant variables can be identified at earliest opportunity. Extensive literature review [32] on behaviour of composite reveal that fibre loading, resin, impingement angle and impact velocity largely influence the composites energy absorption values.

Table 3 Trial angle of experimental using Taguchi method $\left[-15^{\circ} / 40^{\circ} / 75^{\circ}\right]$.

\begin{tabular}{ccccc}
\hline Trial & A & B & C & D \\
\hline S1 & -15 & -15 & -15 & -15 \\
S2 & -15 & 40 & 40 & 40 \\
S3 & -15 & 75 & 75 & 75 \\
S4 & 40 & -15 & 40 & 75 \\
S5 & 40 & 40 & 75 & -15 \\
S6 & 40 & 75 & -15 & 40 \\
S7 & 75 & -15 & 75 & 40 \\
S8 & 75 & 40 & -15 & 75 \\
S9 & 75 & 75 & 40 & -15 \\
\hline
\end{tabular}

In Table 3 each column represents a test parameter whereas each row stands for angle of orientation or test condition. These tables represent combination of parameter levels. In conventional full factorial experiment design, it would require 34 out of 81 runs to study five parameters each at three levels, whereas Taguchi's factorial experiments approach reduces it to only nine runs offering great advantages in terms of experimental time and cost consumed. The experimental observations are further transforms into signal to noise $(\mathrm{S} / \mathrm{N})$ ratio using MINITAB software. The purpose of the MINITAB software is to investigate which design parameters significantly affect the quality of composite characteristic. There are several $\mathrm{S} / \mathrm{N}$ ratios available depending on the type of performance characteristic. In this study, the $\mathrm{S} / \mathrm{N}$ ratios for energy absorption can be express as 'higher is better' characteristic. $\mathrm{S} / \mathrm{N}$ ratios were defined as follows:

$$
\frac{S}{N}=-10 \log \left(\frac{1}{n} \sum_{i=1}^{n} \frac{1}{y_{i}^{2}}\right)
$$

where $n$ is the trial repetition and $y_{i}$ is the result of the $i_{\text {th }}$ experiment for each trial.

\subsection{Twill woven fabrication}

Yarn kenaf fibres were obtained from Kenaf Natural Fibre Industries (Malaysia) Sdn. Bhd. These fibres were chosen due to the abundant resources available in Malaysia. The value of linear density for yarn kenaf is 45tex, simulated and calculated using computed model software, according to the value of yarn kenaf diameter which is $1.0 \mathrm{~mm}$ and density of $1.4 \mathrm{~g} / \mathrm{cm}^{3}$.

Woven fabrics generally consist of two sets of yarns that were interlaced and lie at right angles to each other. The threads that run along the length of the fabric were known as warp ends whilst the threads that run from selvedge to selvedge, that is from one side to the other side of the fabric, were called weft picks. Warp yarns were tensioned within the loom, and weft yarns were inserted and pushed into place to make the fabric. Weft yarns were inserted by a shuttle batted through raised warp yarns. To separate the warp yarns, alternate warp yarns were attached to bars, which will raise the alternate warp yarns. Eventually, the bar was developed into 
heddles and harnesses attached to foot pedals so the weaver could separate the warp yarns by stepping on the pedals, leaving the hands free for inserting the weft yarns.

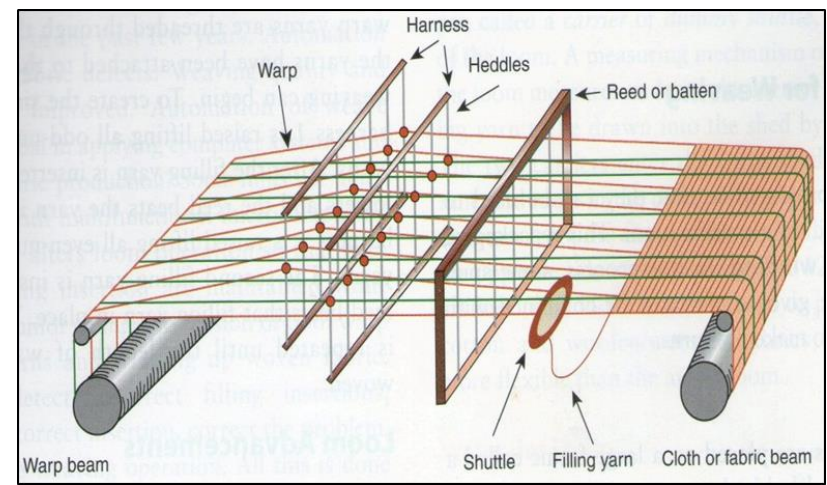

Fig. 2 Simplified drawing of a two-harness shuttle loom [21]

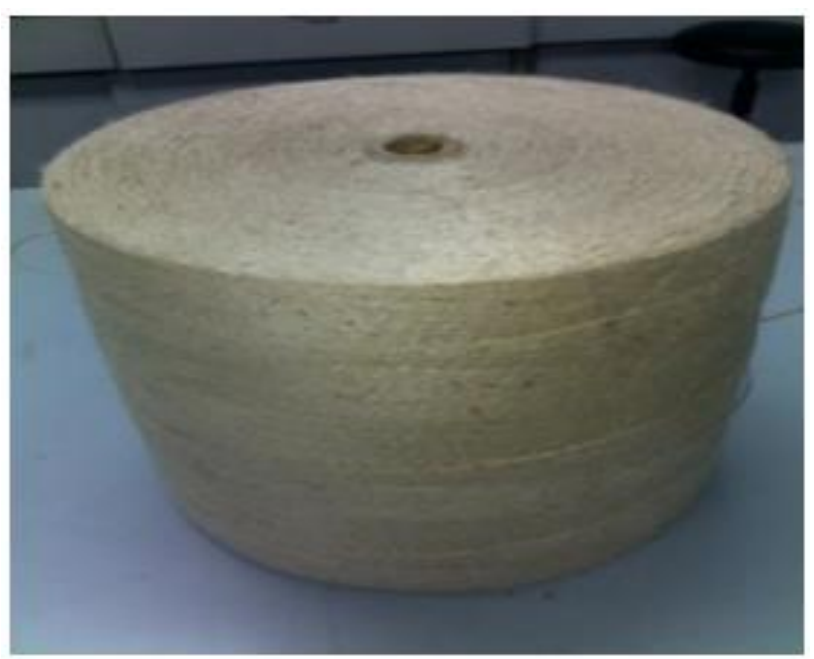

(a)

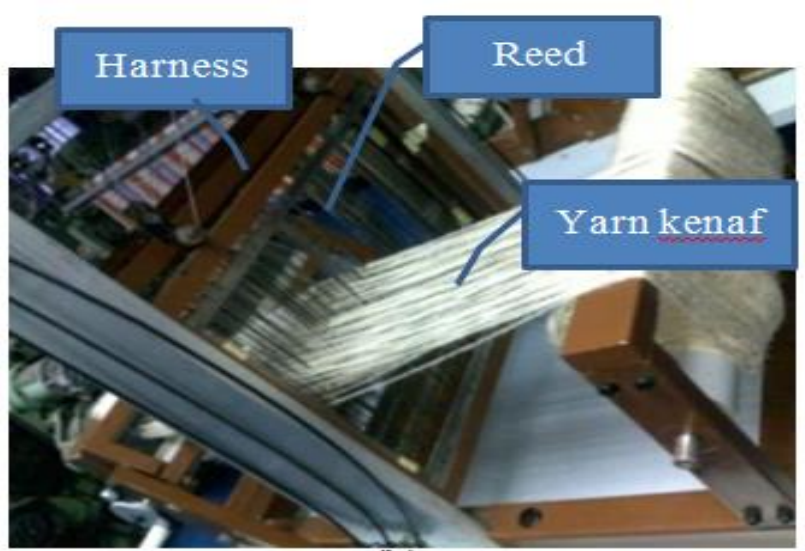

(b)

Fig. 3 Fabrication of woven kenaf (a) yarn kenaf and (b) yarn setup.

The warp was raised and lowered by harnessesheddles arrangement as shown in Fig. 2. A harness is a frame to hold the heddles. The harness position, the number of harnesses, and the warp yarns that were controlled by each harness determine the weave or interlacing pattern. A heddle is a wire with a hole in its centre through which warp yarn was threaded. A reed beats pushed the weft yarns into place to make the fabric firm. The reed was set in a frame and the spaces between the wires were called dents. Warp yarns were threaded through the dents in the reed. The spacing in the reed was related to desired number of warp yarns per inch in the woven fabrication. Reed is available with wide variety of spacing related to the density of the yarns. Carried of weft yarns through shed is called Shuttle. In the shuttle loom, a shuttle was thrown through the shed by picker's sticks at both sides of the loom. The shuttle went to one side and then after the shed has changed, it went back to the other side. The amount of yarns at shuttle loom is limited to weft yarns insertions.



Fig. 4 Twill woven kenaf

Twill woven are selected in this research because, there have higher strength compared to other fabric structure [28]. The angle of twill was determined by the amount of shift in the points of interlacing, which is a one pick-one end shift twill weave and this is called $45^{\circ}$ twill. The yarn kenaf are weaved using handloom machine as shown in Fig 3 (a) and the fibre fabrication for yarn setup is shown in Fig 3 (b).

As for twill weave, each warp or weft yarn floats across two or more weft or warp yarns with a progression of interlacing by one to the right or left. In this study, twill weave that were used are 2:1 which the numerator indicates the number of harness that are raised. The first warp yarn was threaded through a heddle in the first harness, the second warp yarn through a heddle in the second harness, and the third warp yarn through a heddle in the third harness. This process was repeated until the entire set of warp yarns were threaded through the three harnesses. In weaving the first weft yarn, the first two harnesses were raised and the third harness was lowered. For the second weft yarn, the shed changes so that harness 2 and 3 were raised, harness 1 and 3 and lowering harness 2. This were produced the length of float and progression of interlacing described earlier in the definition. This interlacing pattern was repeated until the entire woven was completed. The structure of kenaf twill woven is shown in Fig 4. 


\subsection{Composite preparation}

In order to compare the mechanical performance of each composite, several different parameters were used such as angles and orientations while the fibre volume fraction of kenaf is constant. To strengthen the composite, woven fibres were hardened with polyester resin, which was selected due to its low density and good mechanical strength. The woven fibres were arranged into specific orientation following Taguchi method rule as shown in Table 2. Furthermore, before the samples were placed in mould and compression moulding process started, the mould was sprayed with silicone to facilitate composite was removed from the mould. Fabric with the size of $250 \times 25 \mathrm{~mm}$ which follows accordingly the standard of ASTM D3039 was placed on top of the mould. The specimens were compressed at $1 \mathrm{kPa}$ pressure for 4-6 hour at room temperature. Compressions were conducted by using hydraulic press machine. Laminated kenaf woven were stacked to archive the desired stiffness and thickness. Each lamina was oriented following Taguchi method arrangement to get higher strength of composite. To get the optimal result, three specimens were evaluated for each structure. Fig 5 (c) shows the final sample of four layered twill woven kenaf.

\subsection{Tensile test}

Tensile test was carried out using Universal Testing Machine to characterize the stress/strain behaviours of composites according to ASTM D3039 standard with dimensions of $250 \mathrm{~mm}$ length, $25 \mathrm{~mm}$ width and $3 \mathrm{~mm}$ thick. In order to obtain significant result, three samples were tested for each condition. The speed used in the testing was $5 \mathrm{~mm} / \mathrm{min}$ and conducted at room temperature. These tests determined the behaviour of the specimen such as elongation, nominal strain, Young's modulus and tensile strength. The typical tensile specimens as shown in Fig 6.

The specimens were positioned vertically in the wedge type grips of the testing machine. The grips were then tightened evenly and firmly to prevent any slippage with the gauge length was kept constant at $150 \mathrm{~mm}$. The important part of the specimen was gauge section. Crosssectional area of the specimen gauge section remained from deformation and failed to localize in the region. The gauges length is areas where measurements were made and based on the gauge section. When the test started, the specimen elongates, where the resistance of the specimen increases and was detected by a load cell. The load value was recorded until a rupture in the specimen occurs. The tensile equipment calculates the tensile properties such as tensile strength, yield strength, breaking stress and elongation at break. Universal testing machine that were used for tensile test is as shown in Fig 7.

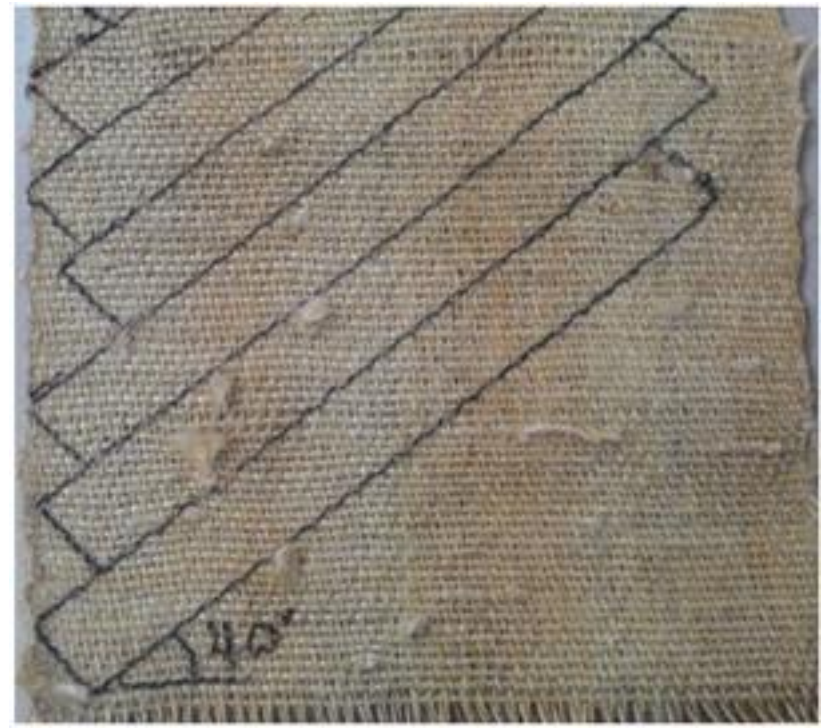

(a)

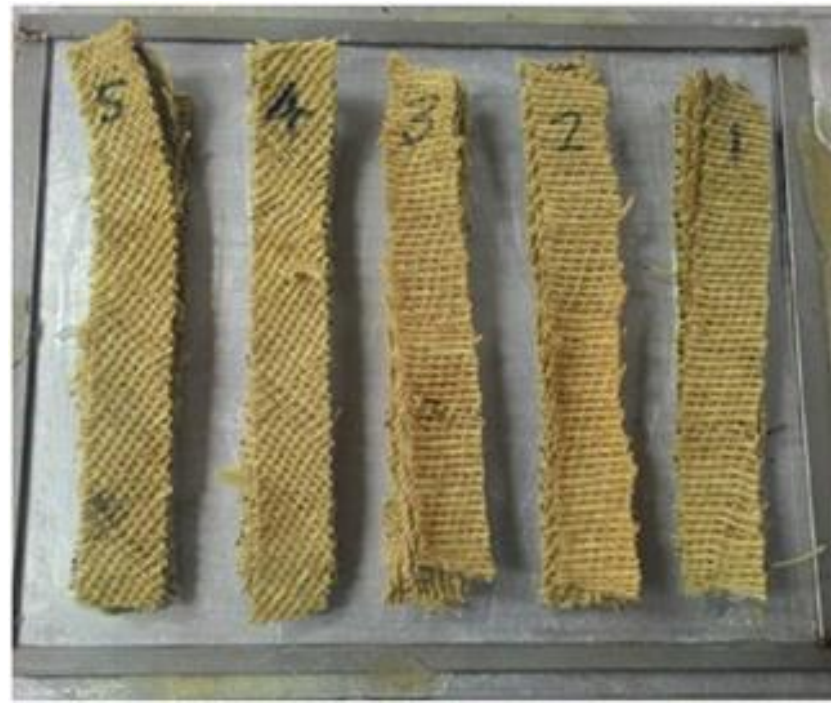

(b)

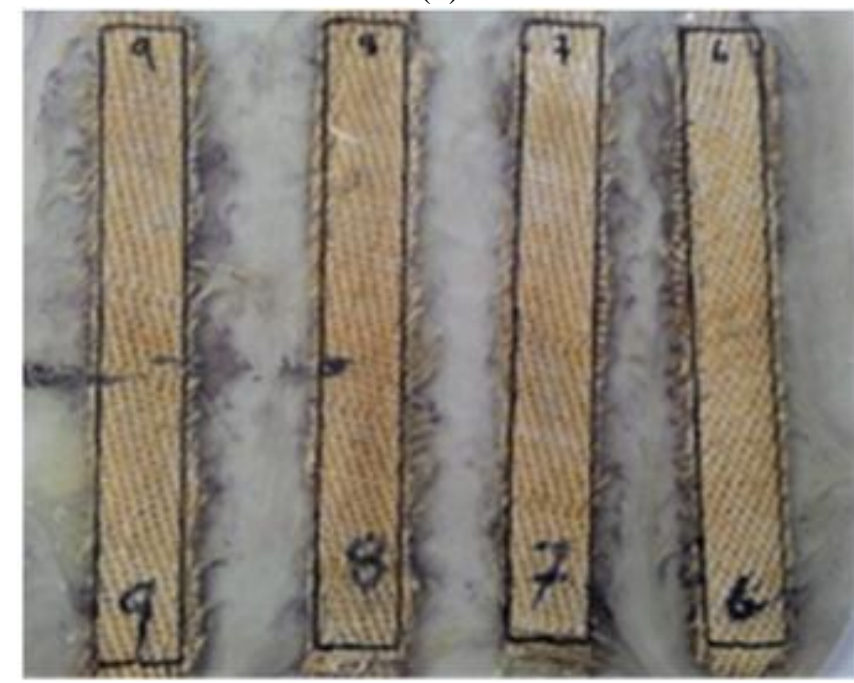

(c)

Fig. 5 Composite fabrication (a) angle of orientations (b) fabric in mould and (c) final sample.

Young's Modulus was calculated by drawing a tangent to the initial linear portion of the stress strain 
curve. Two point on this tangent was selected and the tensile stress was divided by the corresponding strain. For purposes of this calculation, the tensile stress shall be calculated by dividing the load with the average original cross section of the test specimen, as in Equation 2. The result was expressed in $\mathrm{MPa}$.

$$
E=\frac{\sigma}{e}=\frac{P / A}{\Delta L / L}
$$

where, $P$ is a load at point on tangent, $A$ is cross sectional area, $\Delta L$ is elongation at point on tangent and $L$ is initial gage length. Tensile strength was calculated by dividing the load at break by the original cross-sectional area of the material, as in Equation 3. The result was also expressed in MPa.

$$
\sigma=\frac{P}{A_{o}}
$$

where, $P$ is a maximum load at point on tangent and $A_{o}$ is original cross-sectional area.

Another crucial factor for woven fabric was extension percentage. It is defined as the ratio between elongation that a specimen undergoes and its initial length expressed in percentage called extension percentage, as in Equation 4. Breaking extension is the percentage at the breaking point [28].

$$
\varepsilon=\frac{\Delta l}{l}
$$

where, $\Delta l$ is elongation of the gage length of the specimen and $l$ is original gage length.

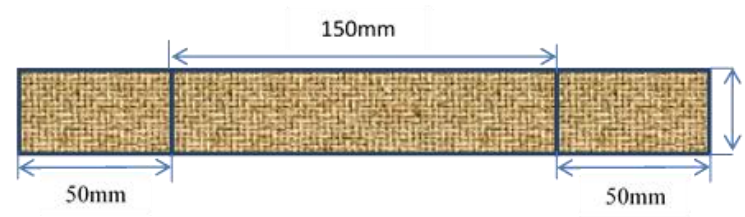

Fig 6. Typical tensile specimen

\section{Results and Discussion}

\subsection{Stress-strain curves of twill woven}

In this study, tensile tests determined the mechanical behaviour of the specimen tested such as, Young's modulus, tensile strength and nominal stress-strain. The test was only conducted to twill woven because it has higher strength compared to other types woven [28, 33]. In order to get higher elastic deformation, the tensile test was carried out on warp position for each sample. Referring to research conducted by [34], warp direction has more strength than the weft direction. In the fabric construction, the warp yarn was firmer. There was low crimp and the presence of ends was more than picks. In a nutshell, the weft yarn has less tensile strength than the warp yarn.

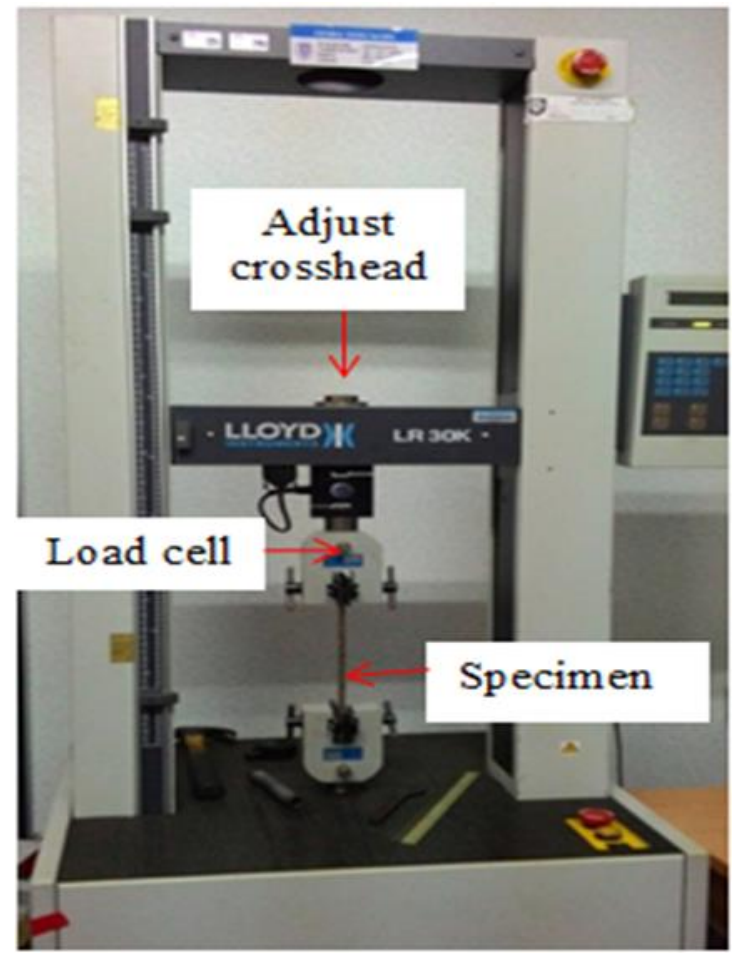

Fig. 7 Universal Testing Machine

The values of Young's modulus were taken from initial linear portion of the stress strain curve. Tensile strength indicates the ability of a composite material to withstand forces that pull it apart as well as the capability of the material to stretch prior to failure. Furthermore, it was considered as one of the most vital aspects for the characterization of woven fabric excellence as well as performance. Tensile strength of a woven was one of the most important properties, which makes it superior in many applications as compared to non-woven fabrics [35-36]. In contrast with other fabrics, woven fabrics showed superior dimensional performance in both vertical and horizontal direction along with utmost cover thread packing compactness [20].

The loads for tensile test were considered under warp axial following the angle of arrangement by Taguchi method. Generally, the warps yarns undergo greater stress than the weft yarns. Warps yarns usually have relatively high twist unlike weft yarns, where the twist was usually kept as low as possible. In previous research [37] investigated the influence of woven structure on mechanical properties. In this research, mechanical strength and modulus in warp direction are higher than those in weft direction. The warp yarns in the laminate are with perform cross angles in parallel or nearly parallel and were being stretched; they would work together to undertake the tensile test resulting in greater tensile strength.

The effects of fibre loadings and lengths on resultant composite's tensile properties were evaluated. Fig 7 shows a typical stress-strain curve from nine samples of twill woven undergone tensile test. The shape of the curve was similar for all samples, where the plotted curve was divided into three stages. Stage 1 represented the 
proportional limit of a material. A material loaded in tension beyond stage 1 when unloaded exhibit permanent deformation. The initial portion of the curve below stage 1 represents the elastic region and approximated by a straight line. The slope of the curve in the elastic regions was defined as Young's modulus.

Stage 2 represents the offset yield strength and was found by constructing a line $0.2 \%$ parallel to the curve in the elastic region. Stage 2 represents the yield strength by extension under load. The ultimate tensile strength or peak stress was represented by stage 3 . Total elongation which includes both elastic and plastic deformation was the amount of uniaxial strain at fracture occurred at stage 3 . Percentage of elongation at break reports the amount of plastic deformation of a material.

From the results obtained in Fig 8, S3 has the highest stress before break as compared to others. This was because of the usage of orientation which was [$15^{\circ} / 75^{\circ} / 75^{\circ} / 75^{\circ}$ and angle of $-15^{\circ}$ resulted in the cross of the position between yarn kenaf composite. Bonding interaction between yarns was very strong. S1 showed lower stress because of their orientation $[-15 \%-15 \%-15 \%$ $15^{\circ}$ ] indicating poor bonding interaction between yarns. Samples S8 and S9 with orientations $\left[75^{\circ} / 40^{\circ} /-15^{\circ} / 75^{\circ}\right]$ and $\left[75^{\circ} / 75^{\circ} / 40^{\circ} /-15^{\circ}\right]$ respectively has maximum strain compared to other woven. This was due to the combination of angle. At the same time, both samples do not have a lot of yarn in the same position and this affected the tensile strength measured. It shows that higher number or yarns in each woven area represents better tensile properties.

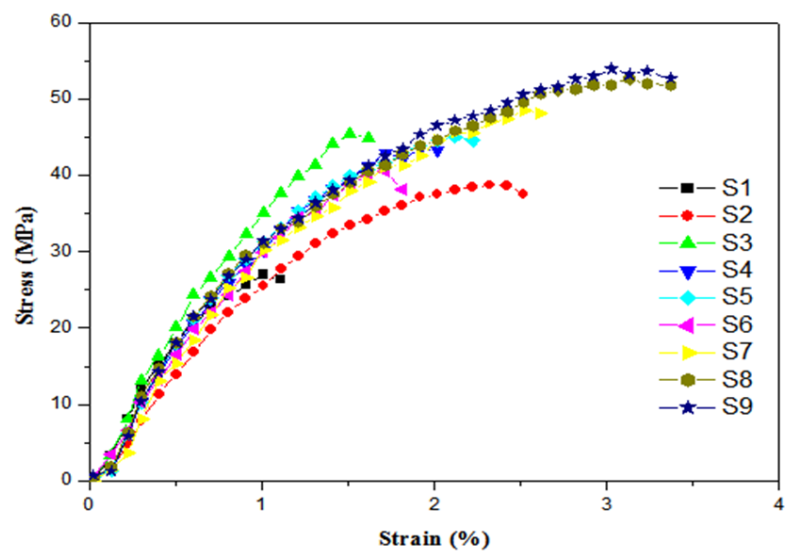

Fig. 8 Stress strain curves of twill woven

According to previous research [38], the tensile strength of a composite material was mainly depended on the strength, modulus of fibre and the effectiveness of the bonding strength between matrix and fibre in transferring stress across the interface. Through the incorporation of kenaf twill woven, the value of stress-strain composites changes when the orientations changed, as shown in Fig 8. It because orientations for each layered gives different elastic stage of each composite. The composites consist of low stiffness matrix with orientation $[-15 \%-15 \%-15 \%$ $\left.15^{\circ}\right]$. The composite behaviour has a closed relationship with fibre interval and interfacial strength and orientation of fibre might be changes the value of mechanical behaviour of composite.

\subsection{Comparing twill woven after optimization}

Fig 8 and 9 showed Young's modulus and tensile strength against nine samples with different orientations. From the result obtained in Fig 8 and 9, the strength was random for each sample. This was due to the mechanical behaviour of composite, where the angle of orientation is the most important part that increased the tensile strength. Due to the result obtained on Fig 9 and 10 after optimization, the new orientation recommended by simulation from Minitab is $\left[40^{\circ} / 75^{\circ} / 40^{\circ} / 40^{\circ}\right]$.

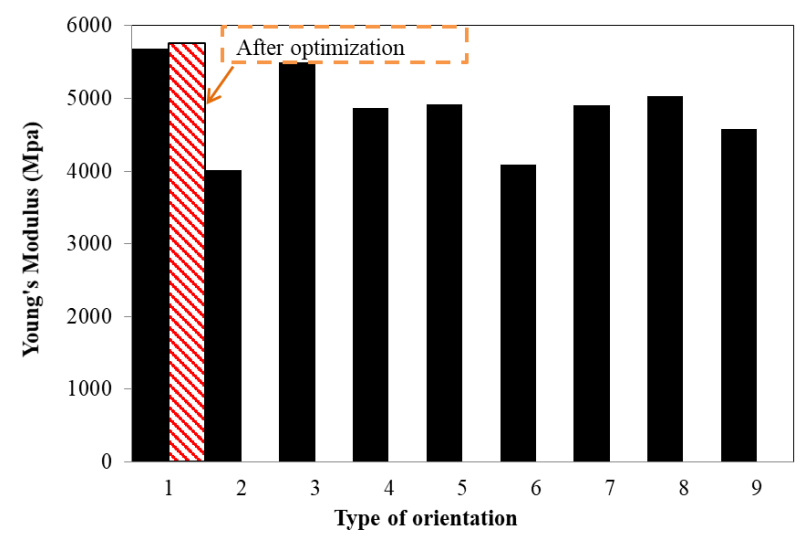

Fig 9. Young's Modulus for twill woven

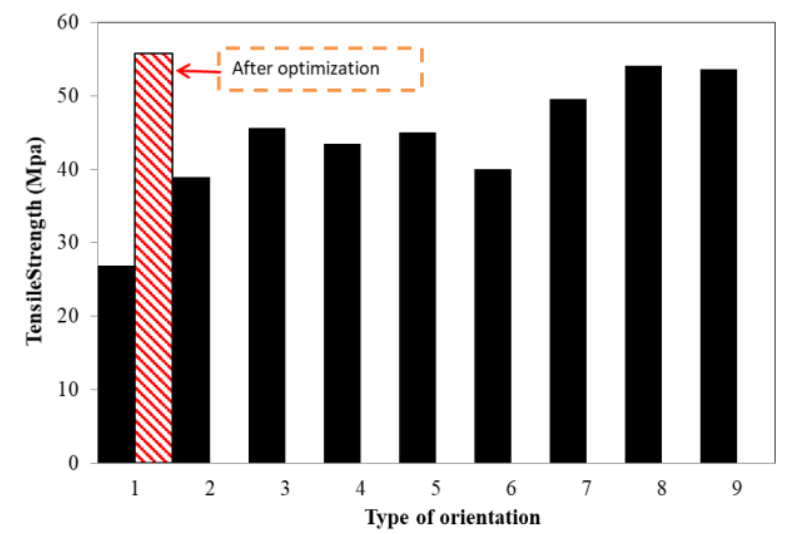

Fig. 10 Tensile strength for twill woven

The value of Young's modulus after optimization was $5761.7 \mathrm{MPa}, 4.23 \%$ higher compared on unoptimized result. Meanwhile, for tensile strength, the value after optimization was $55.7 \mathrm{MPa}, 3.77 \%$ higher compared on un-optimized result. This was due to the fact that twisting yarns with suitable angle improved their tensile strength. Regardless of the fibre material, fibre pattern has been found to influence the composite properties based on the morphological and structural parameters [39]. Taguchi method based, optimization of the parameters are used to produce the best possible quality without increasing any cost. Based on optimization result, Taguchi Method was proved that produce higher modulus elasticity and tensile strength as 
well as the best performance of static loading. Results compared with previous research in Table 4 shows that by using new angle orientation suggested by Taguchi method improved the tensile strength of kenaf fibre composites.

\subsection{Composite fragmentation of twill woven}

Fig 10 presents the comparison of fracture mechanism under axial tensile force among the nine samples. In general, the fracture mechanisms were almost similar where the surfaces rupture was perpendicular to the axis of loading. Generally, the fractured surface indicated that the compatibility between the woven performance for different orientations with polyester resin. From the observation, samples 3 and 4 have large fractured surface compared to others where poor impregnation of yarns at the centre of fracture occurred. Based on the fragmentation reviews, the orientations of yarns was very important to produce a strong bond of a composite. Referring to the fractured surface in Fig 11, the tensile strength of a composite was a reflection of the yarns and the structure of orientations. Sometimes, because of the crimp, the woven strength was less than the strength of twisted yarns, and because of the twist in the yarns, the yarns strength was less than the strength of the woven. However, it was possible to decrease fracture surface and increase the woven strength by rearranging the angle orientations for each layer. Most portion of kinetic energy of the gripped was expended in plastic deformation at the target material before cracking.

Table 4 Comparison mechanical properties of kenaf composites from this research with previous research.

\begin{tabular}{ccccc} 
Ref. & Fibre Type & Resin & $\begin{array}{c}\text { Tensile } \\
\text { Strength } \\
\text { (MPa) }\end{array}$ & $\begin{array}{c}\text { Young } \\
\text { Modulus } \\
\text { (GPa) }\end{array}$ \\
\hline $\begin{array}{c}\text { Current } \\
\text { work }\end{array}$ & $\begin{array}{c}\text { Woven kenaf } \\
\text { (Orientation) } \\
\text { Chopped } \\
\text { Kenaf }\end{array}$ & Polyester & 58 & 5.8 \\
& Epoxy & 26.2 & 1.13 \\
{$[41]$} & $\begin{array}{c}\text { Woven kenaf } \\
\text { (Untreated } \\
\text { NaOH) } \\
\text { Woven kenaf } \\
\text { (Treated } \\
\text { NaOH) }\end{array}$ & Epoxy & 24 & 1.1 \\
{$[41]$} & Epoxy & 27 & 2.9 \\
{$[25]$} & $\begin{array}{c}\text { Woven kenaf } \\
\text { Short fibre }\end{array}$ & $\begin{array}{c}\text { Epoxy } \\
\text { Polyester }\end{array}$ & 16.46 & 0.5 \\
{$[42]$} & $\begin{array}{c}\text { Unidirectional } \\
\text { 30 vol.\% }\end{array}$ & Epoxy & 12.4 & 1.3 \\
{$[42]$} & $\begin{array}{c}\text { Unidirectional } \\
\text { 40 vol.\% }\end{array}$ & Epoxy & 16.4 & 18.4 \\
{$[43]$} & $\begin{array}{c}\text { Long and } \\
\text { discontinuous } \\
\text { Short fiber }\end{array}$ & PP & 18 & 0.7 \\
{$[19]$} & PP & 47 & 4.153 \\
\hline
\end{tabular}

Composite damage might be affected by fibre interval and interfacial strength between fibre and matrix resin because mechanical properties and composite damage were related to the interaction between fibre and resin [40-42]. It was quite difficult to evaluate the effect of composite damage on tensile strength by using actual fibre reinforcement. Therefore, specimens were formed by changing the angle of yarn fibre, the fibre interval and the interfacial strength on tensile strength and the composite damage.

Tensile test on multi fibre orientated showed that tensile strength change when the fibre intervals were widened because the tensile strength was affected by composite damage such as interfacial bonding and fibre break. This demonstrates that composite damage has a close relationship with fibre interval and interfacial strength, and that strength might be increased by controlling them.

\subsection{Fragmentation of twill woven after optimization}

In order to improve strength of a composite, a new orientation as suggested by Minitab software were fabricated. Fig 12 shows the fractured surface of tensile test for will woven after optimization. The orientations that are suggested after analysis of twill were $\left[40^{\circ} / 75^{\circ} / 40^{\circ} / 40^{\circ}\right]$. By comparing with Fig 11 , it can be seen that by using new orientation has improved fracture mechanism. As can be observed, due to the approaching of the matrix crack, tensile normal stress bands was formed in the interface just above the matrix crack, while the rest of the interface was still in compressive stress. By comparing fracture surface before and after optimization in Fig 11 and 12, there was a clear decreasing fractured surface.

Frequently, the fibres were held together by frictional force arising from the disposition of orientations of the structure on composites. Previous research [28] mentioned that, it is unambiguous that the tensile behaviour of a composite is vastly reliant on the weave and orientation designs. Higher interlacements causes higher crimps in the load bearing direction may lead to lower breaking strength and too much larger floats also cause lower breaking strength due of looser structure. Thus, the fractured surface images indicated the compatibility between woven with new orientation verified by using Taguchi method. The angle of orientation was a critical part that can increase the end breakage rate.

\section{Summary}

A natural fibre based composite with a twill of woven reinforced material was fabricated using unsaturated polyester resin. Since there were hundreds of fibre that could be utilized in natural fibre composite, optimization in design of experiments was essential in fabricating natural fibre composite. The objective of these experiments was to understand how Taguchi method works in optimizing the angle orientation that offered the best result in mechanical behaviour to find the best combination of angle arrangements which produce the highest mechanical strength on kenaf twill woven composite. 

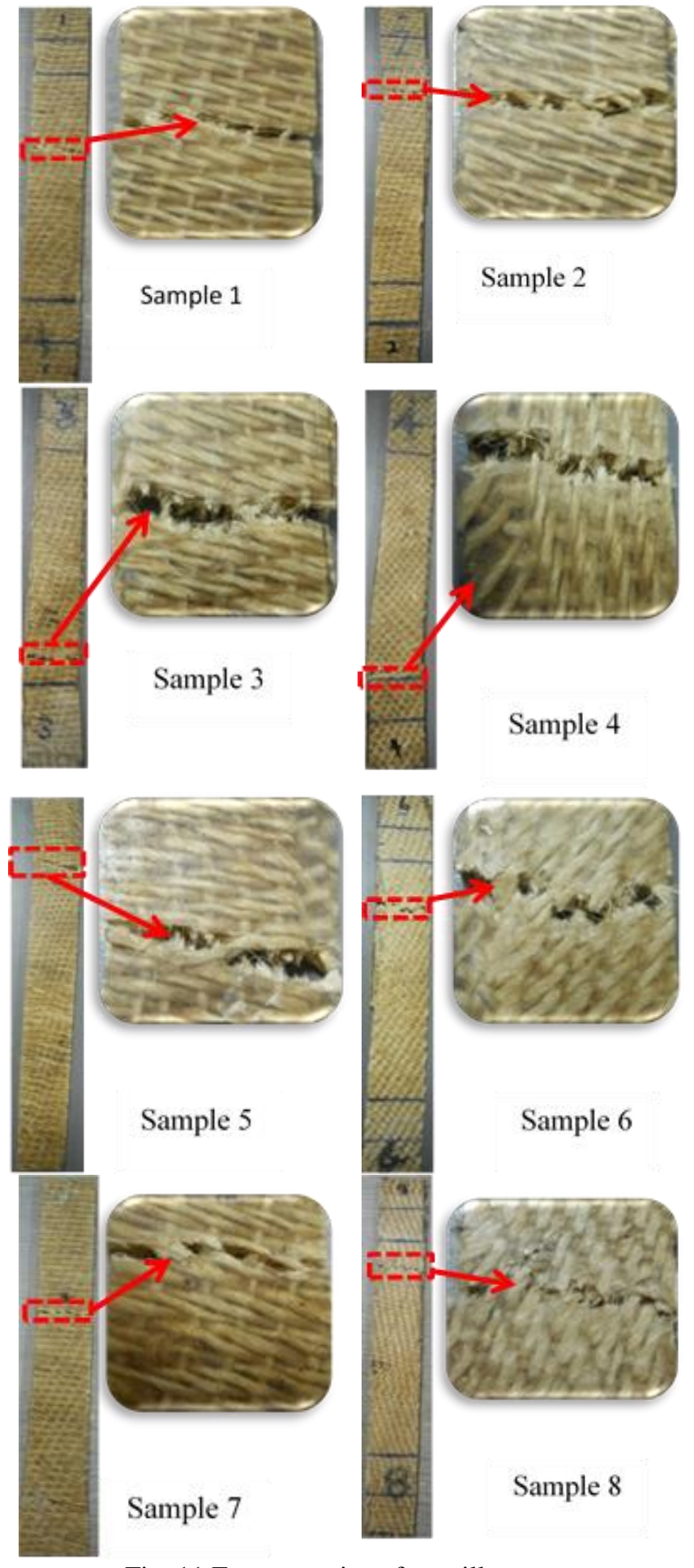

Sample 5

ample 7

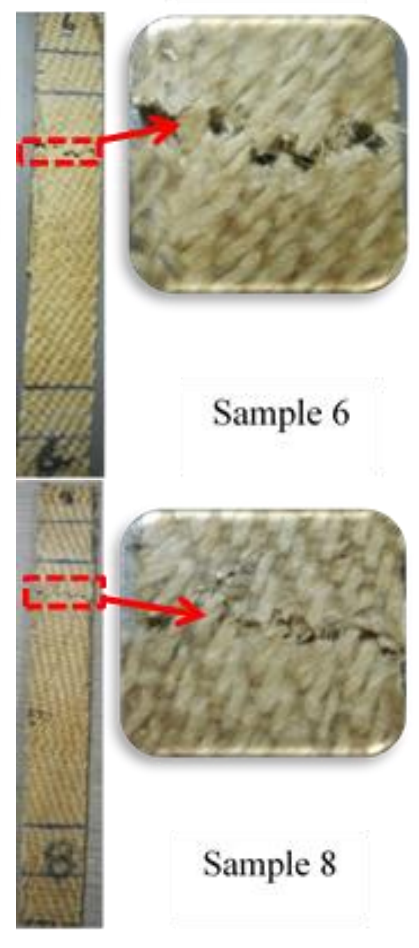

Fig. 11 Fragmentations for twill woven

However, optimizing the selected parameters by Taguchi method was held to produce optimal composites to enhance the properties of fibre composition. In this method, less number of experiments was carried out. Hence, time and cost are reduced considerably. Main analysis was performed based on the average output of the quality characteristic. After the experimental results were fully satisfied, Young modulus and tensile strength of composite were analysed using Minitab software.
From the analysis, the best orientations that produce the highest strength were found. Taguchi method was performed to optimize the fibre orientation with respect to experimental result and to analysing which angle produce high strength to composite.

The experiments were conducted to validate the results obtained by Taguchi orthogonal array. The experimental results were compared with each other. By referring to the result, fibre orientation after optimization produces higher Young's modulus and tensile strength. Therefore, during this study, effectiveness of orientation closure approximately influence on the result. The result shows that the fibre orientation is the most significant fabrication parameter which greatly affects the mechanical behaviour. Experimental results indicated that the orientation for each layered on composite had a significant interaction effect on Young's modulus, and tensile strength. It was proved that the multiple performance characteristic of the woven kenaf reinforced composites can be effectively improved by this method.

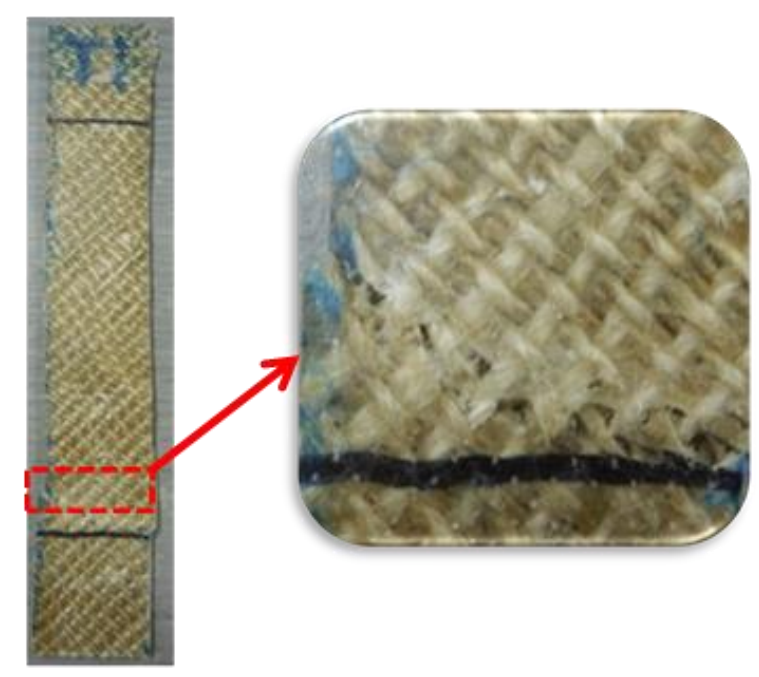

Fig. 12 Fragmentation after optimization

\section{Acknowledgment}

Authors acknowledged Universiti Tun Hussein Onn Malaysia (UTHM), MyBrain15 Scholarship (MyPhd), Office for Research, Innovation, Commercialization and Consultancy Management (ORICC), Center for Graduate Studies UTHM.

\section{References}

[1] Akil, H.M., Omar, M.F., Mazuki, A.A.M., Safiee, S., Ishak, Z.A.M. and Abu Bakar, A. Kenaf fiber reinforced composites: A review. Materials and Design, vol. 32 (2011), no. 8, pp. 4107-4121.

[2] Khalid, S.N.A., Ismail, A.E. and Zainulabidin, M.H. A Review on Effect of Orientation Fabric on Mechanical Energy Absorption Natural Fibres Reinforced Composites. Applied Mechanic and Materials, vol. 773-774 (2015), pp 134-138. 
[3] Othman, A., Abdullah, S., Ariffin, A. K. and Mohamed, N.A.N. Investigation Crushing Behaviour Quasi-Static Oblique Loading on Polymeric Foam Filled Pultruded Composites Square Tubes. Composites Part B: Engineering, vol. 95 (2016), pp. 493-514.

[4] Othman, A., Abdullah, S., Ariffin, A.K. and Mohamed, N.A.N. Investigating the Quasi-Static Axial Crushing Behavior of Polymeric Foam-Filled Composite Pultrusion Square. Material and Design, vol. 63 (2014), pp. 446-459.

[5] Roslan, M.N.N., Ismail, A.E., Hashim, M.Y., Zainulabidin, M.H. and Khalid, S.N.A. Modelling Analysis On Mechanical Damage of Kenaf Reinforced Composites Plates Under Oblique Impact Loadings. Applied Mechanics and Materials, vol. 465-466 (2014), pp. 1324-1328.

[6] Akil, H., Zamri, M.H. and Rosman, M. The Use of Kenaf Fibers As Reinforcements In Composites. Biofiber Reinforcements in Composite Materials 2015, pp. 138-161.

[7] Ismail, A.E., Hassan, M.A. and Kamaruddin, K.A. Perforated Impact Strength of Woven Kenaf Fiber Reinforced Composites. Applied Mechanics and Materials vol. 773-774 (2015), pp. 43-47.

[8] Nishino, T., Hirao, K., Kotera, M., Nakamae, K. and Inagaki, H. Kenaf reinforced biodegradable composite. Composite Science and Technology, vol. 63 (2003), no. 9, pp. 1281-1286.

[9] Grasso, M., Penta, F., Pucillo, G.P., Ricci, F. and Rosiello V. Low Velocity Impact Response of Composite Panels for Aeronautical Applications. Proceedings of the World Congress on Engineering Vol. II WCE 2015, July 1-3, 2015.

[10] Mohamad, Z. Intelligent Signal Processing System to Investigate Damage Severity in Kenaf Fibre Composite. Thesis Doctor of Philosophy, Faculty of Mechanical Engineering and Manufacturing, Universiti Tun Hussein Onn Malaysia, 2016.

[11] Catalin, C., Patachia, S., Papancea, A., Baltes, L. and Tierean, M. Glass Fibres Reinforced Polyester Composites Degradation Monitoring. Applied Surface Science, vol. 358 (2015), pp. 518-524.

[12] Kotik, H. and Ipina, J.P. Frequency Effect in ShortBeam Shear Fatigue of A Glass Fiber Reinforced Polyester Composites. International Journal of Fatigue, vol. 90 (2016), pp. 116-124.

[13] Ramesh, M., Palanikumar, K. and Reddy, K.H. Mechanical Property Evaluation of Sisal-Jute-Glass Fiber Reinforced. Composites Part B, vol. 48 (2013), pp. 1-9.

[14] Li, Y., Zhang, W., Yang, Z.W., Zhang, J.Y. and Tao, S.J. Low-Velocity Impact Damage Characterization of Carbon Fibre. Infrared Physics \& Technology, vol. 76 (2016), pp. 91-102.

[15]El-Gamal, S.E., Al-Nuaimi, A., Al-Saidy, A. and AlLawati, A. Efficiency of near Surface Mounted Technique using Fibre Reinforced. Construction and Building Materials, vol. 118 (2016), pp. 52-62.
[16] Williams D.G.; Baruch, Z. African Grass Invasion in the Americas: Ecosystem Consequences and the Role of Ecophysiology. Biological Invasions, vol. 2 (2000), pp. 123-140.

[17]Bledzki A.K., Sperber V.E. and Faruk, O. Natural and Wood Fiber Reinforcement in Polymer, Rapra Review Reports, vol. 13 (2002), no. 8.

[18] Saba, N. Potential of Bioenergy Production from Industrial Kenaf (Hibiscus Cannabinus L.) based on Malaysian Perspective. Renewable and Sustainable Energy Reviews, vol. 42 (2015), pp. 446-459.

[19]Zampaloni, M., Pourboghrat, F., Yankovich, S.A., Rodgers, B.N., Moore, J., Drzal, L.T., Mohanty, A.K. and Misra, M. Kenaf Natural Fiber Reinforced Polypropylene Composites; A Discussion on Manufacturing Problem and Solution. Composites Part A; Applied Science and Manufacturing, vol. 38 (2007), no. 6, pp. 1569-1580, 2007.

[20]Kumar, R., Kumar, K. and Bhowmik, S. Optimization of Mechanical Properties of Epoxy based Wood Dust Reinforced Green Composite using Taguchi Method. Procedia Material Science, vol. 5 (2014), pp. 688-696.

[21] Yahaya, R., Sapuan, S.M., Jawaid, M., Leman, Z. and Zainudin, E.S. Mechanical Performance of Woven Kenaf-Kevlar Hybrid Composites. Journal of Reinforced Plastic and Composites, vol. 33 (2014), pp. 2242-2254.

[22]Aziz, S.H. and Ansell, M.P. The Effect of Alkalization and Fibre Alignment on the Mechanical and Thermal Properties of Kenaf and Hemp Bast Fibre Composites: Part 1- Polyester Resin Matrix. Composites Science Technology, vol. 64 (2004), pp. 1219-30.

[23]Elsaid, A., Dawood M., Seracino R. and Bobko C. Mechanical Properties of Kenaf Fiber Reinforced Concrete. Construction and Building Materials, vol. 25 (2010), pp. 1991-2001.

[24] Khalid, S.N.A., Jamaludin, M.R., Roslan, M.N., Ismail, A.E. and Zainulabidin, M.H. Effect of LowVelocity Impact on Different Density of Woven Kenaf Reinforced Composites. Journal of Applied Science and Agriculture, vol. 10 (2015), pp. 4-8.

[25] Fraley, S., Oom, M., Terrien, B., Zalewski, J. and Michigan. Chemical Engineering Process Dynamic and Control Open Text Book. Revised 25 May,https//controls.engin.umich.edu/wiki/index.php/ Design of Experiments Via Taguchi Methods Orthogonal Arrays, 2014.

[26] Rostamiyan, Y. Modelling and Analysis of the Tensile and Flexural Properties of A FiberOrientated Hybrid Nanocomposite Using Taguchi Methodology. Strength of Materials, vol. 47, pp. 820-834.

[27]El-Shekeil, Y.A., Sapuan, S.M., Azaman, M.D. and Jawaid, M. Optimization of Blending Parameters and Fiber Size of Kenaf-Bast-Fiber-Reinforced the Thermoplastic Polyurethane Composites by Taguchi Method. Advance in Materials Science and Engineering. Article ID 686452, 2013. 
[28] Ferdous, N., Rahman, M.S., Kabir, R. and Ahmed, A.E. A Comparative Study on Tensile Strength of Different Weave Structures. International Journal of Scientific Research Engineering \& Technology (IJSRET), vol. 3 (2014), pp. 1307-1313.

[29] Kadolph, S.J. Textile 10th Edition, Pearson Education, Inc., Upper Saddle River, New Jersey 07458. Pearson Prentice Hall, 2007.

[30] Dhakal, H.N., Zhang, Z.Y., Richardson, M.O.W. and Errajhi, O.A.Z. The Low Velocity Impact Response of Non-Woven Hemp fibre Reinforced Unsaturated Polyester Composites. Composite Structures, vol. 81 (2006), pp. 559-567.

[31] Mahdi, E., Hamouda, A.M.S. and Sedaey, T.A. The Effect of Fiber Orientation on the Energy Absorption Capability of Axially Crushed Composite Tube. Material and Design, vol. 56 (2014), pp. 923-928.

[32] Prasad, P., Kumar, S.S. and Shastry, S.N. Fabrication and Characterization of Tensile Properties of Laminated Composites-Effect of Fiber orientation. International Journal of Engineering Research \& Technology (IJERT), vol. 2 (2013), pp. 1456-1458.

[33] Brown, D. Morgan, M. and McIlhagger, R. A System for the Automatic Generation of Solid Models Of Woven Structures. Composites Part A: Applied Science and Manufacturing, vol. 34 (2003), pp. 511515.

[34] Gau, L. and Reinfshinder, K. Tensile Failure of Composites, Influence of Interface and Matrix Yielding. Journal of Composite Technology and Research, vol. 14 (1992), pp. 201-210.

[35] Alavudeen, A., Rajini, N., Karthikeyan, S. Thiruchitrambalam, M. and Venkateshwaren, N. Mechanical Properties of Banana/Kenaf FiberReinforced Hybrid Polyester Composites: Effect of Woven Fabric and Random Orientation. Materials and Design, vol. 66 (2015), pp. 246-257.
[36] Nikolic, M., Michailovic, T. and Simovic, L. Real Value of Weave Binding Coefficient as a Factor of Woven Fabric Strength. Fibers Textile Eastern Europe, vol. 4 (2000), pp. 74-78.

[37] Gu, H. Tensile and Bending Behaviour of Laminates with Various Fabric Orientations. Material and Design, vol. 27 (2006), pp. 1086-1089.

[38] Achukwu, E.O., Dauda, B.M. and Ishiaku, U.S. Effect of Fabric Pattern on the Mechanical Properties of Cotton Fabric/Unsaturated Polyester Composites. British Journal of Applied Science \& Technology, vol. 11 (2015), pp. 1-11.

[39] Yang, L., Wu, Z., Gao, D. and Liu. X. Microscopic Damage Mechanisms of Fibre Reinforced Composite Laminates Subjected to Low Velocity Impact. Computational Materials Science, vol. 111 (2016), pp. 148-156.

[40] Yahaya, R., Sapuan, S.M., Jawaid, M., Leman, Z. and Zainudin, E.S. Effect of Layering Sequence and Chemical Treatment on the Mechanical Properties of Woven Kenaf-Aramid Hybrid Laminated Composites. Materials and Design, vol. 67 (2014), pp. 173-179.

[41]Reza, M., Jamaludin, M.Y., Abdul Rahman, M.S. and Mehdi, R. Characteristics of continuous unidirectional kenaf fiber reinforced epoxy composites. Materials \& Design, vol. 64 (2014), pp. 640-649.

[42] Al Emran Ismail, Azmahani Sadikin, Mohd Nasrull Abdol Rahman, Shahruddin Mahzan, Salihatun Md. Salleh, Sufizar Ahmad, Mohd Baharudin Ridzuan. Crushing performances of axially compressed woven kenaf fiber reinforced cylindrical composites, International Journal of Integrated Engineering, vol. 10, No. 1 (2018), pp. 189-195. 